\title{
Survey on Status of Prosthodontists in Nepal, Service Rendered and Their Level of Satisfaction
}

\author{
Maharjan $\mathrm{SK}^{1 *}$, Mathema $\mathrm{S}^{2}$ \\ ${ }^{1}$ Assistant Professor, Department of Prosthodontics, People's Dental College and Hospital, Kathmandu, Nepal. \\ ${ }^{2}$ Professor, Department of Prosthodontics, People's Dental College and Hospital, Kathmandu, Nepal.
}

\begin{abstract}
Purpose: This survey aims to gather cumulative data on Prosthodontists in Nepal, their academic, financial and work status, services rendered and satisfaction level on job, lab support, material availability and work place environment.

Material and methods: Online form was developed for the purpose of survey regarding "Status of Prosthodontists in Nepal, Service rendered and their level of satisfaction". The online survey form was sent to Prosthodontists as per data available in Nepalese Prosthodontic Society. Data analysis was done from response obtained from November $1^{\text {st }}$ to December $25^{\text {th }}, 2017$.

Results: Among the 77 Prosthodontists whom the survey form were sent, 65 Prosthodontists responded ( $85 \%$ ). The male were $55 \%$ and female $45 \%$, majority of age ranges from 31 to 40 years. $81.5 \%$ had Master of Dental Surgery (MDS) degree and 52.3\% had post graduation from Nepal. $80 \%$ of Prosthodontists are practicing in private institute including dental colleges, hospital and clinics. Among the academic degree, 1 tutor, 36 Assistant Professor, 4 Associate professor and 5 professors were recorded. $50 \%$ of Prosthodontists had original research article and case report published. Regarding the job satisfaction, lab support, material availability and working environment, most of them were satisfied.

Conclusion: Number of Prosthodontists in Nepal are in growing trend. Most of them are of young age. Prosthodontic services rendered are growing in diverse aspect and most of them were satisfied with their job and work
\end{abstract}

Key words: Prosthodontists, Status, Services, Satisfaction level, Nepal

\section{Introduction}

$\mathrm{P}$ rosthodontic services were known to be started in Nepal as earlier as 1929 when few pioneers obtained training from India and provided dental services limited to high class Rana families. Dental treatment during those days was limited to extraction of mobile tooth and replacing with vulcanite partial and full

\footnotetext{
*Corresponding Author

Dr. Shyam K. Maharjan, Assistant Professor, Department of Prosthodontics and Maxillofacial Prosthetics, People's Dental College and Hospital, Kathmandu

E-mail:maharjan_sk@hotmail.com
}

dentures. In 1941, qualified dentists with LDS, DDS degree started their practice using foot engine, kerosene stoves and making Vitallium dentures and soldered gold crowns ${ }^{1}$

The first dental surgeon to obtain Master in Dental Surgery (MDS) degree in Prosthodontics was from KGMC, Lucknow, India in the year 1982..$^{2-4}$ The first MDS program under Nepalese University was conducted under the joint collaboration of Kathmandu University and MCODS, Mangalore, India. In Nepal, the academic program in MDS in Prosthodontics was first started in NAMS Bir Hospital in 2008 following with People's Dental 
College Hospital, Kathmandu under Tribhuvan University, started MDS in Prosthodontics in 2009 and BPKIHS, Dharan in 2010.

Number of Prosthodontists has tremendously increased since then with their involvement in academic, clinical and research activities. However, there is lack of data regarding the status of Prosthodontists in Nepal. This survey aims to gather the information of Prosthodontists in Nepal, their education status, work place, Prosthodontic Services rendered and satisfaction level of job, lab support, material availability and work place environment

\section{Material and methods}

Online form was developed in Jotform for the survey regarding "Status of Prosthodontists in Nepal, Service rendered and their level of satisfaction". The survey form contained personal information, education status, work place, Prosthodontic Services provided and satisfaction level on job, lab support, material availability and work place environment. The online survey form was sent to 77 Prosthodontists registered as specialist in Nepal Medical Council as per data in Nepalese Prosthodontic Society. Online form was sent to all the registered Prosthodontists including members as well as non-members of the Nepalese Prosthodontic Society. The survey was open for response from November $1^{\text {st }}$ to December 252017.

\section{Results}

The objective of the survey was to obtain current information regarding the Registered Prosthodontists practicing in Nepal, Services rendered and their level of satisfaction. Among 77 participants whom the survey form were sent, 65 participants responded $(84.41 \%)$. Following are the result derived from survey (Figure 1)

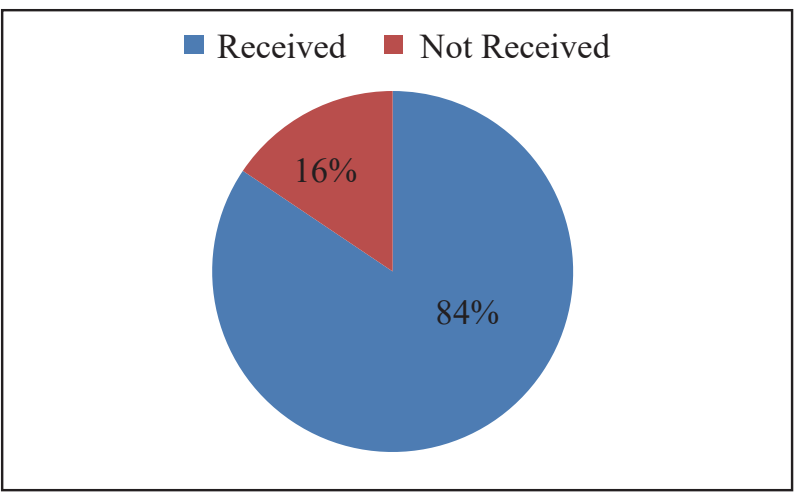

Figure 1: Responses of Survey

\section{Number of Prosthodontists with year of post graduation}

According to the responses of the survey, first Prosthodontists in Nepal had post graduation in the year 1982. Number of Prosthodontists was limited to 12 until 2009. However the number had significantly increased from 2011. (Figure 2)

\section{Number of Prosthodontist with year of post graduation \\ No. of Prosthodontist}

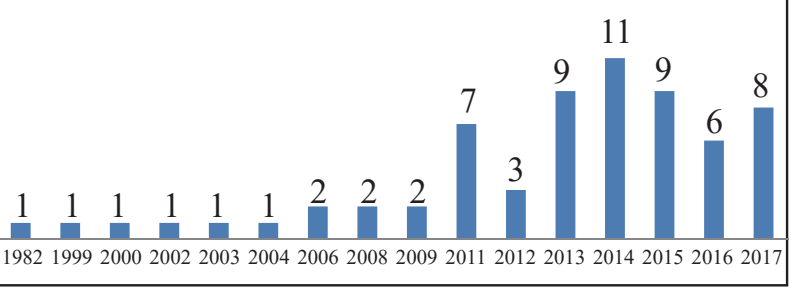

Figure 2: Number of Prosthodontists with year of Graduation

\section{Gender of Prosthodontists}

Data showed that $55 \%$ of Prosthodontists were male and $45 \%$ were female. (Figure 3 )

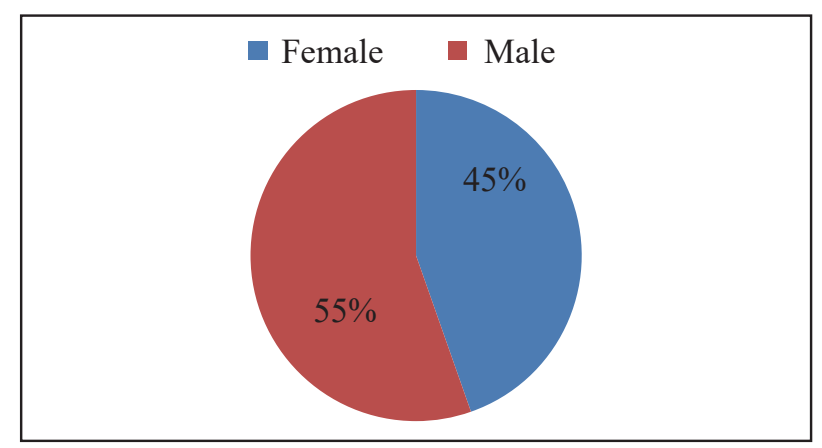

Figure 3: Gender of Prosthodontists 


\section{Age of Practicing Prosthodontics}

Survey showed that $11 \%$ of respondents were under the age of $30.75 \%$ of them ranged from 31 to 40 years, $9 \%$ were from 41 to 50 years and only $5 \%$ were above 50 years (Figure 4). Average age of practicing Prosthodontists was 35.6 years

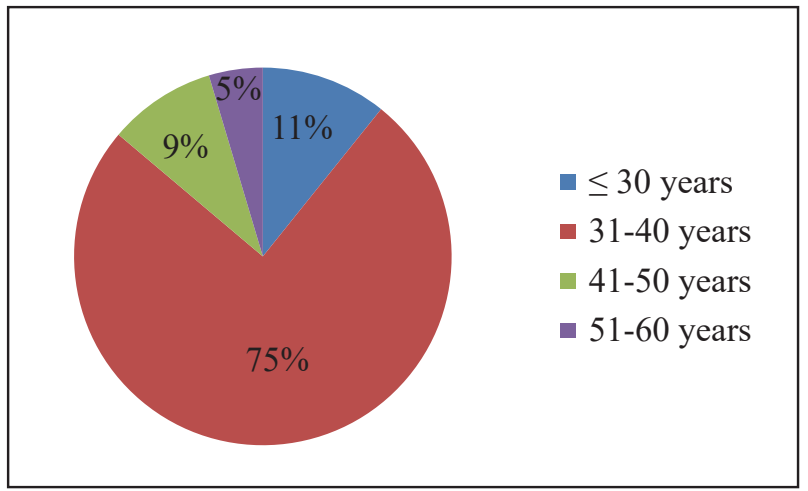

Figure 4: Age of Practicing Prosthodontists

\section{Type of Post Graduation Degree}

Survey response indicated the post graduation degree were mainly four types -Master of Dental Surgery (MDS), Master of Surgery (MS), Master of Science in Dentistry (M. Sc. D) and Fellow of College of Physician and Surgery, Pakistan (FCPS). $81.5 \%$ of Post Graduation Degree was Master of Dental Surgery (MDS) (Figure 5)

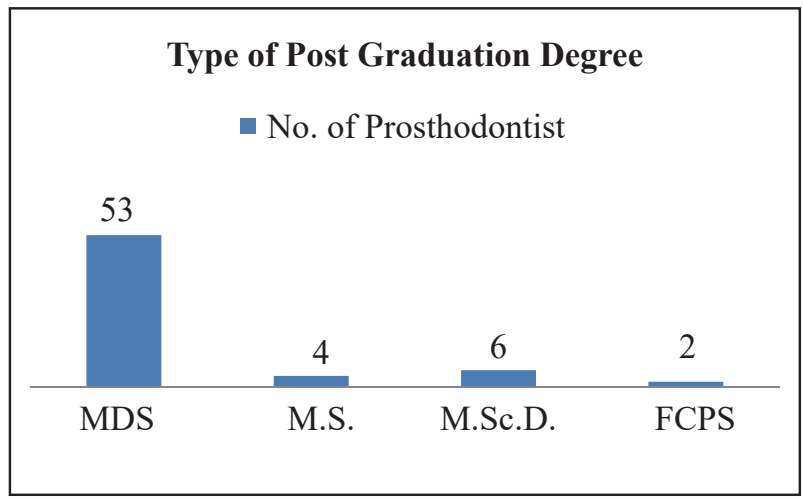

Figure 5: Type of Post Graduation Degree

\section{Country of Post Graduation}

Survey response shows that $52.3 \%$ of Prosthodontists had completed post graduation for Nepal, $20 \%$ from China, $16.9 \%$ from SARRC Countries. (Figure 6)

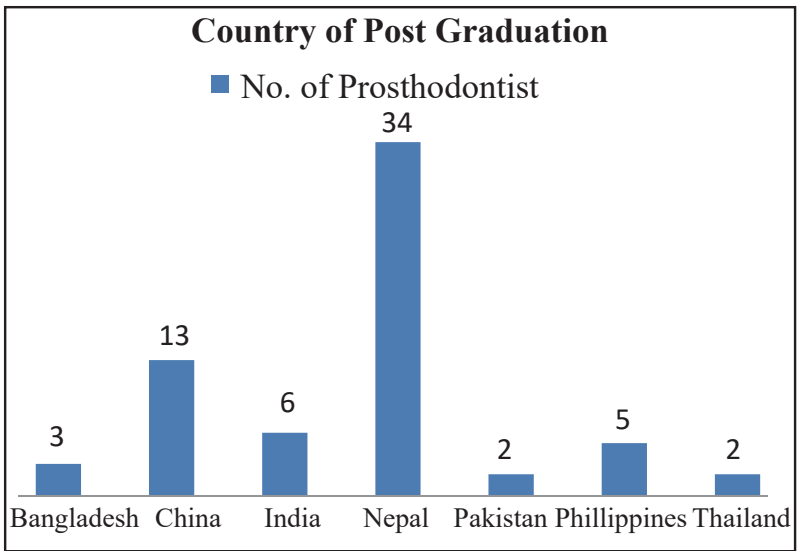

Figure 6: Country of Post Graduation

\section{Years of Practice since Completion of a Post Graduation}

Among 65 respondants, $66.1 \%$ of Prosthodontists practiced for about 5 years and only one $(1.5 \%)$ practiced for more than 31 years. (Figure 7)

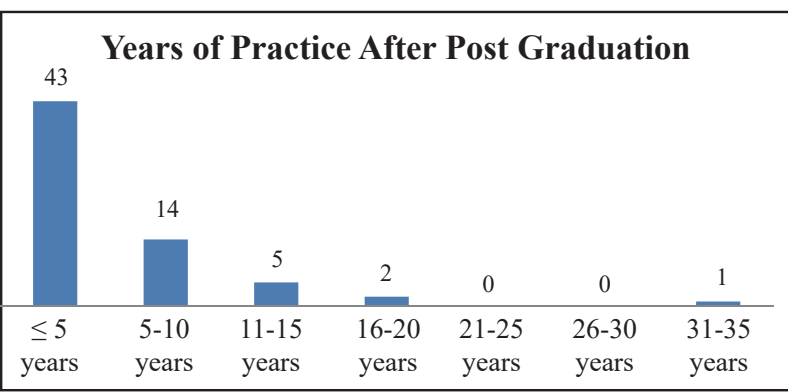

Figure 7: Years of Practice since Completion of a Post Graduation

7. Area of Service of Prosthodontists in Nepal

Among 65 respondants, $20 \quad \% \quad$ (13 Prosthodontists) are in Nepal government and semi government services. $78.4 \%$ (51) of them are practicing in private institute including dental colleges, hospital and clinics, among which 75\% are engaged in Private Dental Colleges. (Figure 8)

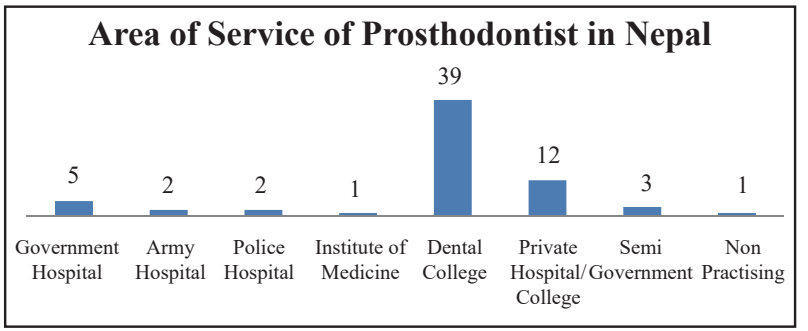

Figure 8: Area of Service of Prosthodontists in Nepal 
8. Job Type of Prosthodontists in Nepal

Survey data showed that 4 Prosthodontists (4\%) are full time academician, $18(27.6 \%)$ are full time clinician, 22 (33.8\%) are working as both academician and clinician while $18(27.6 \%)$ are also involved in research activity. Data shows less number of Prosthodontists involved in full time research. (Figure 9)

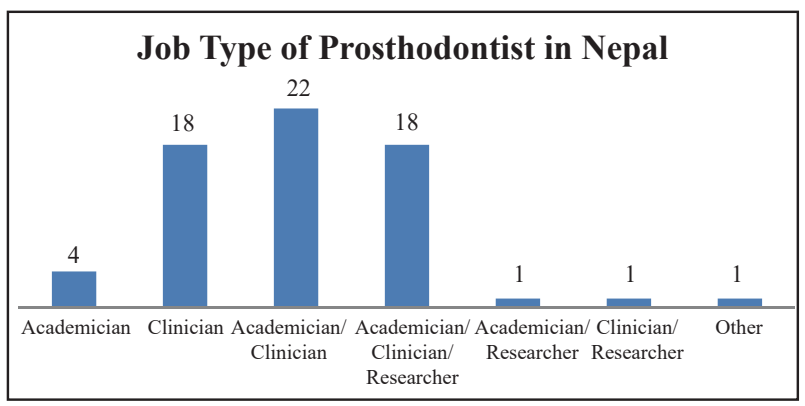

Figure 9: Job Type of Prosthodontists in Nepal

9. Status of Prosthodontists in Academic

Among prosthodontists involved academically, 1 tutor, 36 Assistant Professor, 4 Associate professor and 5 Professors in Prosthodontics were observed. The maximum number of prosthodontists $36(78.2 \%)$ involved in academic were at the level of Assistant Professor. (Figure 10)

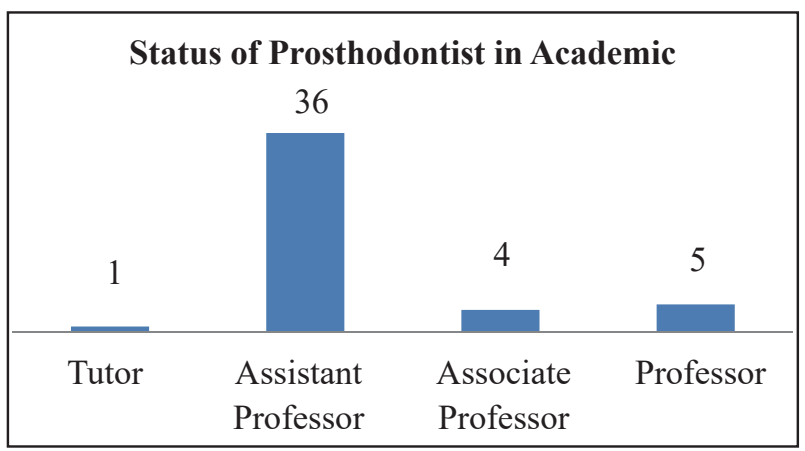

Figure 10: Status of Prosthodontists in Academic

\section{Number of Work Place of Prosthodontists}

According to responses of this survey, $47.6 \%$ of Prosthodontists are involved in single institute (Dental college/ Dental Hospital / Dental Clinic) while $50.7 \%$ of Prosthodontists are associated with more than one work place. Only 1 Prosthodontists was not into the clinical practice. (Figure 11)

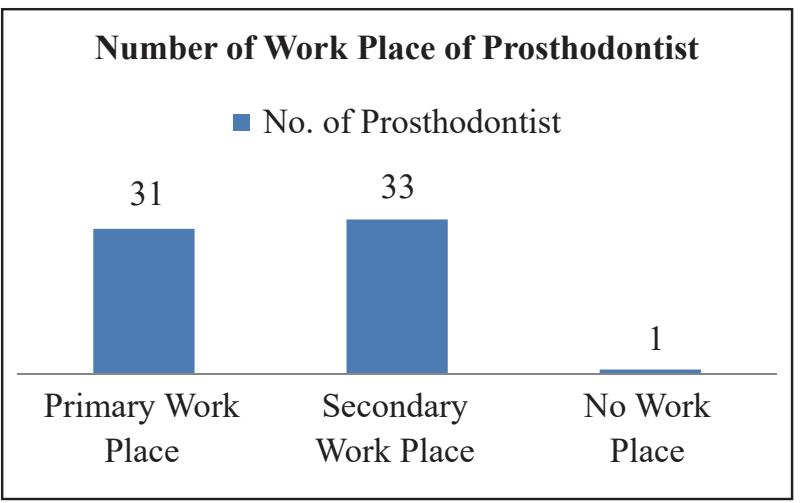

Figure 11: Number of Work Place of Prosthodontists

\section{Location of Practice of Prosthodontists}

Among the 65 responses of this survey, $67.9 \%$ of Prosthodontists are practicing within the Kathmandu Valley while $29.23 \%$ of Prosthodontists are practicing outside the Kathmandu valley and 3\% of Prosthodontists are abroad (Figure 12)

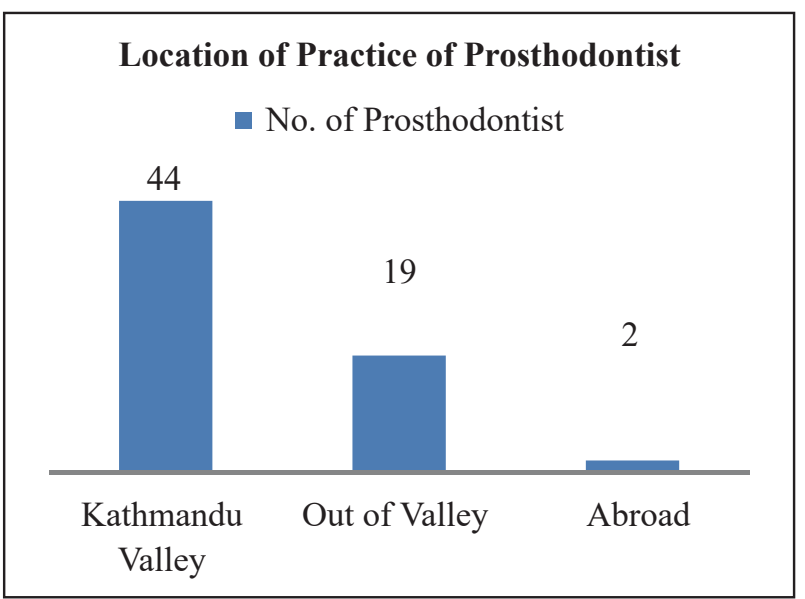

Figure 12: Location of Practice of Prosthodontists

\section{Type of Prosthodontic Practice}

Survey data highlighted that $100 \%$ of Prosthodontists are practicing Removable and Fixed Dental Prosthesis and $81.5 \%$ are practicing implant prosthodontics. (Figure 13). According to this survey, Treatment and Transtional denture are least practised modality in removable prosthesis. Maxillary obturator are the commonly practised maxillofacial prosthesis. Sleep apnea device, full arch implant rehabilitation, ear, nose finger prosthesis are the less practised maxillofacial prosthesis in Nepal (Figure 14) 


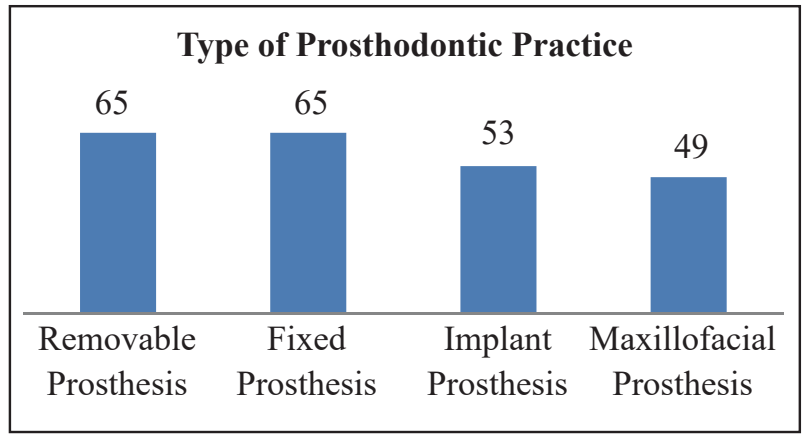

Figure 13: Type of Prosthodontic Practice

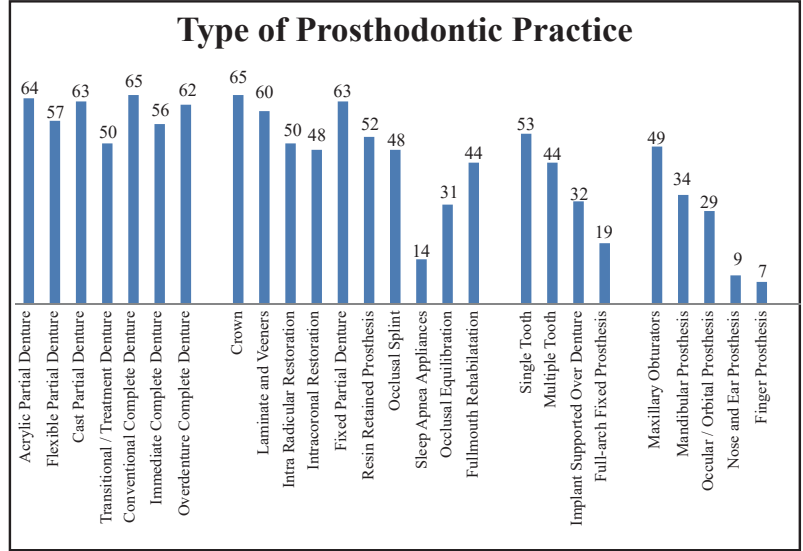

Figure 14: Type of Prosthodontic Practice

13. Annual Income of Prosthodontists

Regarding the annual income, result of this survey showed that $60 \%$ of Prosthodontists generate annual income of Rs 5,00,000/to Rs $15,00,000 /-$ while $26.15 \%$ of Prosthodontists annual income was less than Rs 5,00,000/- and 3\% of Prosthodontists annual income was above Rs 25,00,000/(Figure 15)

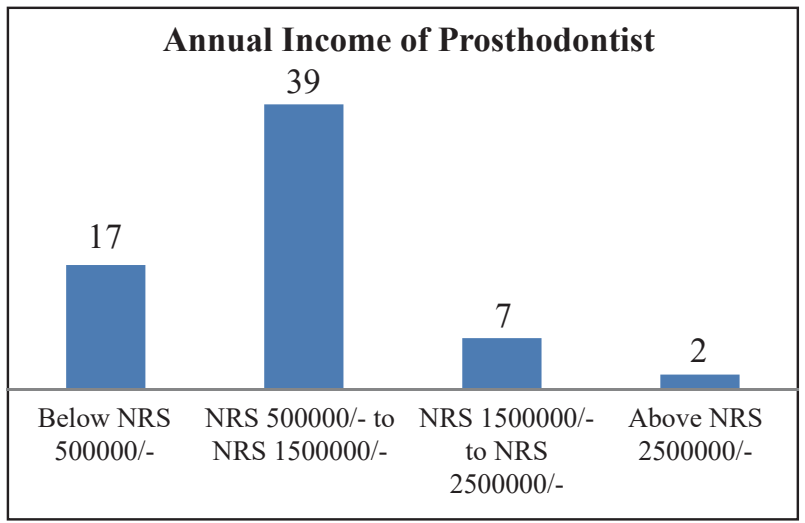

Figure 15: Annual Income of Prosthodontist

\section{Paper Publication and Presentation}

Regarding the publication, this survey showed that original research articles were the most common followed by case report. 23\% of Prosthodontists had original research publication, $12.3 \%$ had case report publication, $18.4 \%$ had publication on both original research as well as case report but $32.3 \%$ of Prosthodontists had no publication. (Figure 16) Regarding paper presentation, this survey showed that case report was the common presentation followed by original research paper. 16.9 $\%$ of Prosthodontists had case report presentation, $12.3 \%$ had presentation on original research, $15.38 \%$ had both original research as well as case report presentation but $36.9 \%$ of Prosthodontists had not done any presentation. (Figure 16)

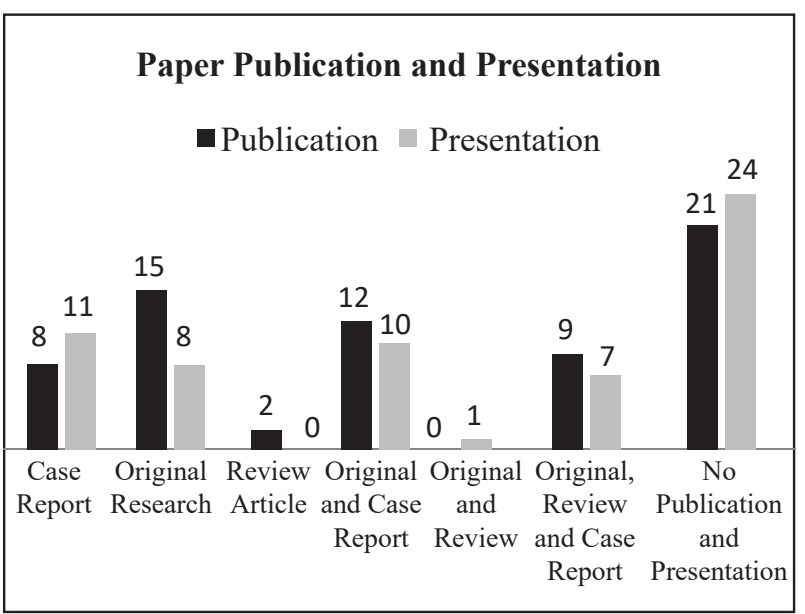

Figure 16: Paper Publication and Presentation

\section{Rating of Satisfaction by Prosthodontists}

In the survey, respondent were asked to rate the job satisfaction, lab support, material availability and working environment. This survey showed that around 50\% of Prosthodontists had rated in ok state regarding the job satisfaction, lab support, material availability and working environment. $32.3 \%$ had rated better and $15.38 \%$ had rated best score on job satisfaction with $33.8 \%$ better and 10.76 $\%$ best score on working environment. However, 24.6\% responsed bad and $23 \%$ better on lab support and $18.46 \%$ responsed bad on material availability. Table 1 
Table 1: Rating of Satisfaction by Prosthodontists

\begin{tabular}{|l|c|c|c|c|c|}
\hline & Worst & Bad & Ok & Better & Best \\
\hline Job Satisfaction & 0 & 3 & 31 & 21 & 10 \\
\hline Lab Support & 1 & 16 & 33 & 15 & 0 \\
\hline Material Availability & 0 & 12 & 34 & 1 & 3 \\
\hline Working Environment & 0 & 3 & 33 & 22 & 7 \\
\hline
\end{tabular}

\section{Discussion}

Formal post graduate education on Prosthodontics was started in Nepal with the establishment of dental colleges, institutes and commencement of MDS program in Nepal in 2008. All dental graduates had to go outside Nepal to do post graduation before that time. First Prosthodontists in Nepal had post graduated in the year 1982 and after a long gap of 17 year, second Prosthodontists in the year 1999. Nepal had only 11 Prosthodontists untill $2008^{5}$ but this number had significantly increased to more than 70 by the end of 2017 .

Number of Prosthodontists had increased tremendously after post graduation education started in Nepal after 2008. According to the survey, 14 Prosthodontists were registered in the year 2014 which is highest number among years. This survey showed 55\% Prosthodontists were male and $45 \%$ were female despite the fact that $58 \%$ of dental surgeons were female in $2008^{5}$. This fact indicate male dominance in this field,which was also in harmony with results of a Survey published by American College of Prosthodontists where $78 \%$ of responding were male. $^{6}$

This survey showed that $11 \%$ of Prosthodontists were under or equal to the age of 30 years, $75 \%$ of age range from 31 to 40 and only 5\% above the age of 50 indicating the dominance of late young population in Nepal. American College of Prosthodontists survey report showed $60.37 \%$ of practicing Prosthodontists were above the age of 45 years and only $39.64 \%$ of Prosthodontists were below the age of 44 years. ${ }^{6}$
This survey data showed $47.6 \%$ of Prosthodontists were involved in single institute (Dental college/ Dental Hospital / Dental Clinic) while $50.7 \%$ of Prosthodontists were associated with more than one work place. $67.9 \%$ of Prosthodontists were practicing within the Kathmandu Valley while 29.23\% of Prosthodontists were practicing outside the Kathmandu valley. $15.3 \%$ Prosthodontists are working in Nepal government services while $80 \%$ of Prosthodontists were practicing in private institute. $6.1 \%$ of Prosthodontists were full time academician, $27.6 \%$ full time clinician, $33.8 \%$ as both academician and Clinician. This trend indicated that most of the Prosthodontists were academically involved along with private practice mainly in the capital kathmandu. The data of this survey also indicated that among academically involed Prosthodontists, majority were at the level of assistant professor. This survey showed most Prosthodontists involved in academic have paper publication and presentation. Numbers of Prosthodontists involved in research activities were comparatively less.

This survey also showed that $100 \%$ of Prosthodontists were rendering different treatment modalities on removable and fixed dental prosthesis along with implant supported prosthesis in their practise. However, maxillofacial prosthesis and full arch implant rehabilitation were less practised by most of them. This trend in Nepal is slightly different from the trend in United States of America, according to Survey by Eckert et al which 
showed $82 \%$ Prosthodontists use implantsupported prostheses in their practice ${ }^{7}$.

This survey highlighted that $60 \%$ of Prosthodontists generate annual income of Rs $5,00,000 /-$ to Rs $15,00,000 /-, 26.15 \%$ annual income less than Rs 5,00,000/- and only 3\% annual income above Rs 25,00,000/-indicating the financial status of this profession.

Regarding the data on the job satisfaction, lab support, material availability and working environment, $50 \%$ of Prosthodontists had rated satisfactory, $32.3 \%$ better and $15.38 \%$ rated best score on job satisfaction but $24.6 \%$ responded bad and $23 \%$ better score on lab support and $18.46 \%$ bad on material availability. This showed job and working environment of Prosthodontists were in satisfactory condition but need improvement in lab support and material availability.

\section{Conclusion}

Within the limitation of this study, following conclusions has been done

1. Number of Prosthodontists has increased tremendously after post graduation education started in Nepal

2. There is dominance of male (55\%) and late young Prosthodontists (age 31-40 year) in the population of Prosthodontists in Nepal

3. Most of the Prosthodontists are academically involved with private practice, mainly in the capital kathmandu.
4. Among academically involed Prosthodontists, majority are at the level of assistant professor. Most Prosthodontists involved in academic have paper publication and presentation.

5. Prosthodontists are rendering different treatment modalities on removable and fixed dental prosthesis along with implant supported prosthesis in their practise. Maxillofacial prosthesis and full arch implant rehabilitation are less practised by most of them..

6. Job and working environment of Prosthodontists are in satisfactory condition but need improvement in lab support and material availability.

\section{References}

1. Shrestha BB. In: Shrestha RM, Journal of Nepal Dental Association, 1998.

2. Shrestha RM. Dental Directory. First ed.: Nepal Dental Association, 2004.

3. Maharjan SK. Dental Directory. Second ed.: Nepal Dental Association, 2008.

4. Pradhan B. Dental Directory. Third ed.: Nepal Dental Association, 2012.

5. Shrestha S, Maharjan SK. Facts about Nepalese Dentists. Dentistry Nepal. 2008.

6. Nash KD. 2017 Survey of Prosthodontistss, Results of a Survey. American College of Prosthodontistss, 2017.

7. Eckert SE, Koka S, Wolfinger $\mathrm{G}$ and Choi YG. Survey of implant experience by Prosthodontistss in the United States. Journal of prosthodontics : official journal of the American College of Prosthodontistss. 2002; 11: 194-201. 